\title{
Tidal and seasonal changes in the temporal and spatial distribution of foraging Carcinus maenas in the weakly tidal littoral zone of Kerteminde Fjord, Denmark
}

\author{
A. Aagaard ${ }^{1}$, C. G. Warman ${ }^{2}$, M. H. Depledge ${ }^{2}$ \\ ${ }^{1}$ Biologisk Institut, Odense Universitet, Campusvej 55, DK-5230 Odense M, Denmark \\ ${ }^{2}$ Ecotoxicology \& Marine Biology Research Group, Department of Biological Sciences, University of Plymouth, \\ Drake Circus, Plymouth PL4 8AA, England
}

\begin{abstract}
Seasonal and tidal changes in foraging activity of the shore crab Carcinus maenas were investigated from August 1992 to May 1993 in Kerteminde Fjord, Funen, Denmark. Foraging activity was 15 to 20 times higher in summer and autumn than in winter and spring. Despite the weakly tidal conditions at the study site a significant proportion of the crab population exhibited tidal rhythmicity in foraging activity. Detailed examination revealed that it was predominantly early intermoult (green ventral carapace), male crabs that behaved in this way. Females constituted ca $20 \%$ of the crabs caught throughout the year and were active primarily at night, independent of the tidal phase. In constant conditions in the laboratory, the majority of male crabs displayed endogenous heart rate rhythms in phase with expected tidal and diel cycles at their collection sites. Non-green male crabs did not exhibit rhythmicity to the same degree. Juvenile crabs comprised a greater proportion of the total catch at low tide than at high tide. The findings are compared with earlier studies on $C$. estuarii (earlier $C$. mediterraneus) in similar tidal conditions in the Mediterranean Sea
\end{abstract}

KEY WORDS: Carcinus maenas Foraging - Colour forms - Rhythmic variation - Weak tidal change

\section{INTRODUCTION}

Carcinus maenas exposed to significant tidal changes express tidal, diurnal, semilunar and seasonal modulations of behaviour. Within populations however, inter-individual behavioural differences associated with sex, size (age) and moult stage are apparent. With regard to the latter, the various intermoult stages can be recognised by gradual changes in the colour of the carapace (from green in early intermoult to orange and red/brown forms if intermoult is prolonged - see Kaiser et al. 1990, McGaw et al. 1992). Carapace colouration (which is most readily assessed by examining the ventral carapace) can be related to differences in behaviour patterns in adult C. maenas (Hunter \& Naylor 1993). 'Non-green' C. maenas (i.e. all colour forms from orange to red/brown) tend to remain in the subtidal zones below the Low-Water Mark (LWM) regardless of tidal and diurnal changes in the environment. The juveniles of both sexes are located predominantly in the intertidal zone [between the LWM and the High-Water Mark (HWM)] irrespective of the state of the tide (Hunter \& Naylor 1993). However, adult green male C. maenas usually forage actively in the intertidal zone at flood tide, withdrawing below LWM with the ebbing tide. This segregation of $C$. maenas into behaviourally distinct groups has been verified in the laboratory by examining differences in the expression of endogenous circatidal and circadian rhythms (Naylor 1958, McGaw \& Naylor 1992, Reid et al. 1993) and in situ (Naylor 1962, Crothers 1968, Dare \& Edwards 1981, Hunter \& Naylor 1993, Warman et al. 1993). In winter, when water temperature decreases, C. maenas will migrate into deeper water 
and remain there, without expressing significant tidal changes in their behaviour. In spring, when temperature rises again, rhythmic locomotor activity resumes (Naylor 1962, Crothers 1968, Atkinson \& Parsons 1973, Rasmussen 1973).

A search for endogenously driven rhythms in locomotor activity in Carcinus estuarii from the Mediterranean Sea failed to detect circatidal rhythmicity (Naylor 1961, Warman et al. 1991). Consequently, it might reasonably be hypothesised that in the similar, weakly tidal environment of Kerteminde Fjord, Denmark (tidal range 10 to $30 \mathrm{~cm}$; The Royal Danish Administration of Navigation and Hydrography) C. maenas would also fail to express tidal rhythms.

The distance between LWM and HWM around Kerteminde Fjord is ca 1 to $2 \mathrm{~m}$ and constitutes only a small part of the foraging habitat of crabs located there. It should also be noted that wind effects on water level in the fjord often greatly exceed those due to tidal forces.

In the present study, variations in the distribution and activity of Carcinus maenas in Kerteminde Fjord were examined throughout the year. Also, inter-individual differences in behaviour were assessed in situ. Free-running rhythms were investigated in constant laboratory conditions by measuring changes in heart rate, which has recently been shown to be a useful indicator of endogenous rhythms in crabs, and is readily measured (Aagaard et al. 1991, in press).

\section{MATERIALS AND METHODS}

Field studies. Shore crabs Carcinus maenas were collected in Kerteminde Fjord, Funen, Denmark $\left(55^{\circ} 26^{\prime} 12^{\prime \prime} \mathrm{N}, 10^{\circ} 36^{\prime} 54^{\prime \prime} \mathrm{E}\right)$, during 5 separate 24 to $28 \mathrm{~h}$ periods from August 1992 to May 1993 (4 Aug 1992, 18 Aug 1992, 6 Oct 1992, 10 Feb 1993, 2 May 1993). Six sampling stations were evenly distributed along a transect perpendicular to the coast (Table 1). The inner 4 stations (Stns 0 to 3) were distributed along a pier. The pier thus provided access to shallow water sampling stations without disturbing the biota. The remaining 2 stations (Stns 4 and 5) were located off the end of the pier and marked with anchored buoys. A boat moved by pulling a floating wire along the transect was used when sampling from these outermost stations

Dropnets enabled crabs to be sampled every hour at each station. Six dropnets ( 1 at each station) were submerged on the seabed for 5 min every hour over periods of 24 to $28 \mathrm{~h}$. Each dropnet was constructed of a $70 \mathrm{~cm}$ diameter iron frame covered with a net of $20 \mathrm{~cm}$ depth (1 mm mesh size). The dropnets were baited with fresh pieces of raw herring prior to each sampling exercise. The bait was located in bags constructed of fine plastic mesh to prevent the crabs from eating it. The crabs caught were examined, and sex, size (carapace width, $\mathrm{CW}$ ) and colour of the abdomen recorded. Seawater level and water temperature at the time of sampling were noted. To simplify classifications based on abdomen colour, data will be presented here under the designations 'green' or 'non-green', the latter covering all intermediate colour forms ranging from orange to red/brown. All crabs were released at their respective sampling stations immediately after the above data had been obtained.

Yearly variations in the intensity and pattern of foraging were examined by comparing seasonal sampling data. Differences in the expression of foraging activity in relation to tidal stage and diel phase were investigated by allocating the crabs collected to groups on the basis of their sex, size and colour.

Endogenous rhythms in the laboratory. The expression of endogenous rhythms in heart rate was compared in 8 green and 8 non-green adult male Carcinus maenas (CW: 49 to $63 \mathrm{~mm}$ ). Immediately after collection of 4 representatives of each colour morph, heart rates were monitored simultaneously using noninvasive infrared techniques (Depledge \& Andersen 1990, Aagaard et al. 1991). Crabs were immobilised using perforated, body-sized containers and recordings made in constant conditions (dark, temperature $15^{\circ} \mathrm{C}$, salinity $20 \%$ ) in aerated sea water. Heart rates were continuously measured as beats per minute (bpm) for $4 \mathrm{~d}$. Data were stored on computer diskette for later analysis. Recorded heart beats per minute were reduced to mean heart rates (bpm) for successive 20 min periods. Overall trends in the time series were removed using a moving average of $24 \mathrm{~h}$ span to subtract the trend prior to periodogram analysis (Williams \& Naylor 1978).

\section{RESULTS}

Data from 5 individual sampling exercises were analysed to determine changes in the temporal and spatial distribution of Carcinus maenas. 
Table 2. Carcinus maenas. Seasonal variation in catch frequency, size, sex and colour proportion of collected crabs

\begin{tabular}{|c|c|c|c|c|c|}
\hline & 4 Aug 1992 & 18 Aug 1992 & 6 Oct 1992 & 10 Feb 1993 & 2 May 1993 \\
\hline Total catch & 424 & 770.00 & 471.00 & 36.00 & 29.00 \\
\hline Mean dropnet catch & 3.40 & 4.60 & 3.00 & 0.20 & 0.20 \\
\hline Mean male size $(\mathrm{mm}) \pm \mathrm{SD}$ & $44.8 \pm 10.0$ & $39.7 \pm 9.7$ & $38.7 \pm 9.4$ & $37.8 \pm 7.7$ & $49.5 \pm 14.4$ \\
\hline Mean female size $(\mathrm{mm}) \pm \mathrm{SD}$ & $37.7 \pm 6.4$ & $33.7 \pm 6.9$ & $32.2 \pm 9.8$ & $33.3 \pm 5.5$ & $34.1 \pm 5.3$ \\
\hline Mean water temperature $\left({ }^{\circ} \mathrm{C}\right)$ & - & 17.80 & 11.10 & 3.00 & 11.70 \\
\hline Female proportion (\%) & 20.30 & 19.60 & 38.60 & 22.20 & 24.10 \\
\hline Non-green males (\%) & 23.70 & 13.40 & 12.60 & 12.50 & 42.90 \\
\hline Non-green females (\%) & 25.60 & 10.60 & 14.90 & 14.30 & 22.70 \\
\hline Night catch $(\%)$ & 45.05 & 38.18 & 78.34 & 100.00 & 31.03 \\
\hline
\end{tabular}

\section{Influence of season on crab abundance, size and colour (moult stage)}

There was a significantly higher catch of Carcinus maenas in Kerteminde Fjord during the summer and autumn sampling periods, than in winter and spring $(p<0.05$, Student's $t$-test; Table 2 ), when data were expressed as catch per dropnet. Minimum $\mathrm{CW}$ was $17 \mathrm{~mm}$ and the maximum $81 \mathrm{~mm}$ (Fig. 1). Male crabs had on average a 6 to $7 \mathrm{~mm}$ greater CW than females. The relative proportions of each intermoult stage (green, orange and red) are presented in Fig. 1. Late intermoult stages (red) did not appear until females and males were above 30 to $35 \mathrm{~mm} \mathrm{CW}$. The mean CW of males and females varied from 37.8 to $49.5 \mathrm{~mm}$ and 32.2 to $37.7 \mathrm{~mm}$, respectively, throughout the seasons. Mainly large males were caught in May while large females were caught principally during early August (Table 2). The proportion of females caught was consistently around $20 \%$ of the total catch, except during the autumn when $39 \%$ of the crabs were females. The non-green proportion of C. maenas represented 10 to $15 \%$ of the population except in early August and May when they were more abundant ( 23 to $43 \%$ ). The proportion that crabs caught at night contributed to the total catch varied with season (31 to $100 \%$ ).

\section{Influence of season on catch abundance along an intertidal-sublittoral transect}

A seasonal pattern was evident in the abundance of Carcinus maenas caught along a transect. In February and May few crabs were caught at the inner stations
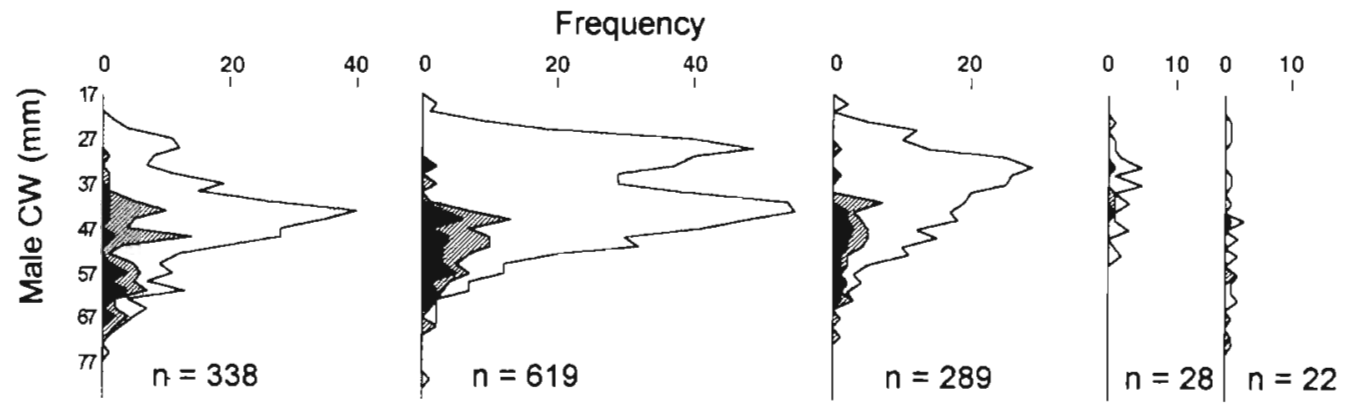

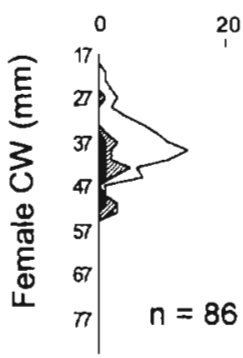

4 August

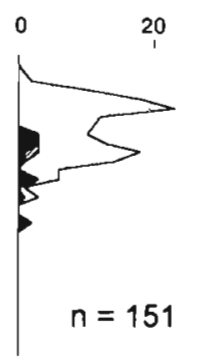

18 August

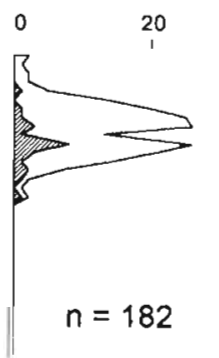

6 November 10 February 2 May

Fig. 1 Carcinus maenas. Seasonal variation in size distribution of colour forms of male and female crabs. Dotted area: green forms; hatched area: orange forms; solid area: red forms; n: total number of each sex collected at that time 
Table 3. Carcinus maenas. Total number of crabs caught at each station over the 5 sampling exercises. Number of non-green crabs given in parentheses

\begin{tabular}{|c|c|c|c|c|c|c|c|c|c|c|}
\hline \multirow[t]{2}{*}{ Stn } & \multicolumn{2}{|c|}{4 Aug 1992} & \multicolumn{2}{|c|}{18 Aug 1992} & \multicolumn{2}{|c|}{6 Oct 1992} & \multicolumn{2}{|c|}{10 Feb 1993} & \multicolumn{2}{|c|}{2 May 1993} \\
\hline & Female & Male & Female & Male & Female & Male & Female & Male & Female & Male \\
\hline 0 & - & - & $10(3)$ & $91(13)$ & $68(6)$ & $62(8)$ & 0 & 0 & 0 & 0 \\
\hline 1 & $23(6)$ & $92(15)$ & $25(5)$ & $133(23)$ & $39(5)$ & $62(5)$ & 2 & $2(1)$ & 0 & 0 \\
\hline 2 & $11(2)$ & $54(24)$ & $19(1)$ & 71 (11) & $17(1)$ & 41 (5) & 1 & 2 & 0 & 0 \\
\hline 3 & $18(4)$ & $82(20)$ & $28(1)$ & $83(12)$ & $17(3)$ & $31(7)$ & 2 & 6 & 0 & $6(1)$ \\
\hline 4 & $25(10)$ & $73(11)$ & $32(5)$ & $125(13)$ & $28(4)$ & $60(8)$ & 1 & $12(2)$ & $2(1)$ & $6(1)$ \\
\hline 5 & $9(1)$ & $37(10)$ & $37(1)$ & $116(11)$ & $13(4)$ & 33 (11) & $2(1)$ & $6(1)$ & $5(2)$ & $10(3)$ \\
\hline Total & $86(23)$ & $338(80)$ & $151(16)$ & $619(83)$ & $182(23)$ & $289(44)$ & $8(1)$ & $28(4)$ & $7(3)$ & $22(5)$ \\
\hline
\end{tabular}

(Stns 0 to 2 ; Table 3), while the number of females caught in early October at Stn 0 was high. The distribution of crabs among the stations was similar in August and October (Table 3).

\section{Changes in crab distribution and moult stage with season}

Data from August and October were analysed separately to determine the relations among sex and colour (moult stage) and sampling station. This was investigated in a 3-way contingency table using the simplest model of fit. Contingency analysis indicated a 3-way interaction between location, sex and colour in the first data set collected in early August ( $\mathrm{df}=1, G^{2}=11.2, \mathrm{p}=$ 0.001 ). Testing the variables pairwise revealed a significant fit for colour and location of the crabs ( $\mathrm{df}=3$, $\chi^{2}=10.99, p<0.05$ ) whereas testing sex and location or sex and colour pairwise failed to reveal significant interactions $\left(\mathrm{df}=3, \chi^{2}=2.29, \mathrm{p}=0.51\right.$ and $\mathrm{df}=1, \chi^{2}=$ $0.24, p=0.62$ respectively). The main differences between expected and observed abundance of crabs in the contingency table of location versus colour were reduced numbers of green Carcinus maenas at Stn 1 and a higher abundance of non-green individuals at Stn 2. A similar analysis of the data collected on 18 August 1992 indicated a 2-way interaction between location and sex $\left(\mathrm{df}=11, G^{2}=17.06, \mathrm{p}>0.05\right)$. Testing the fit of this model of expected sex abundance at each location indicated fewer females than expected at the 2 innermost stations and higher numbers than expected at the 4 outer stations. The opposite was observed for the males ( $\left.\mathrm{df}=5, \chi^{2}=11.79, \mathrm{p}<0.05\right)$. The last of the collections made on 6 October 1992 (when a greater number of crabs were collected) indicated a 2-way interaction between location and sex or colour ( $\mathrm{df}=6$, $G^{2}=2.07, p=0.91$ ). Testing the model of interactions between sampling station and sex of individuals revealed a higher number of females than expected at Stn 0 (df $\left.=5, \chi^{2}=16.37, p<0.001\right)$ (see Table 3). The contingency table of location and colour led to rejection of the null hypothesis, i.e. there were no interactions between the 2 variables ( $\mathrm{df}=5, \chi^{2}=15.16, \mathrm{p}<$ 0.01 ). There were less non-green and more green $C$. maenas observed than expected at the inner stations (Stns 0 to 2) and the opposite at the outer stations (Stns 3 to 5).

\section{Did the state of the tide and diel phase influence foraging activity?}

The 3 collections of Carcinus maenas in August and October were also analysed as a single data set along the transect to randomise for tidal stage and diel phase. Every hour of sampling from each of the three $24 \mathrm{~h}$ sampling periods was assigned to 1 of 4 categories: (1) high tide period during the day; (2) low tide period during the day; (3) high tide period during the night; (4) low tide period during the night. High tide periods were defined as the $3 \mathrm{~h}$ before and the $3 \mathrm{~h}$ after the time of high tide. The same principle was used to define low tides. Nights were defined as being from sunset to sunrise and days from sunrise to sunset. The mean number of crabs collected per hour in each of these 4 tidal/diel categories was calculated and standardised with regard to the number of sampling stations (Table 4). Two-way ANOVA was used to test the influence of tide and diel stage on average catch per dropnet. This indicated that significantly more crabs

Tabie 4. Carcinus maenas. Mean catch per dropnet at the 4 tidal/diel stages (see 'Results' for definitions of day, night and high and low tides)

\begin{tabular}{|rcccc|}
\hline \multirow{2}{*}{$\begin{array}{l}\text { Sampling } \\
\text { date }\end{array}$} & \multicolumn{2}{c}{ Day } & \multicolumn{2}{c|}{ Night } \\
& Low tide & High tide & Low tide & High tide \\
\hline 4 Aug 1992 & 3.23 & 4.14 & 7.26 & 4.75 \\
18 Aug 1992 & 6.78 & 6.53 & 8.00 & 6.54 \\
6 Nov 1992 & 1.57 & 2.73 & 5.43 & 8.68 \\
\hline
\end{tabular}




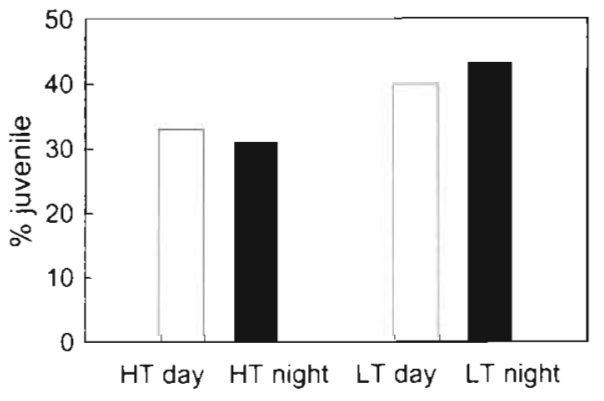

Fig. 2. Carcinus maenas. Proportion of juveniles in relation to adult crabs collected at different tidal and diel stages. HT: high tide; LT: low tide

were caught at night than during the day $(F=8.08, \mathrm{p}<$ 0.01 ; Tukey post hoc test: $p<0.01$ ). Tidal stage did not appear to influence the number of crabs caught per hour.

\section{Was the size of crabs related to the type of foraging behaviour exhibited?}

Comparing the juvenile proportion of the total catch (August and October data) at both the inner and outer stations around high and low tide revealed a significantly higher proportion of juveniles in the catch at low tide $(10$ to $11 \%)$, regardless of the time of day or night. The proportions of juveniles at high tide and low tide during the day and at night are shown in Fig. 2. The results of Student's $t$-test are shown in Table 5. Generally, a higher proportion of juveniles ( 5 to $7 \%$ ) was caught at the outer stations (Stns 3 to 5 ).

The relation between size and foraging activity of green and non-green male, and female Carcinus

Table 5. Carcinus maenas. Juvenile proportion of total catch of crabs at high and low tide, compared at the inner and outer stations and at all stations together

\begin{tabular}{|lccc|}
\hline Location & High tide & Low tide & $\mathrm{p}$ \\
\hline Stns 0 to 2 & 28.5 & 39.9 & $<0.05$ \\
Stns 3 to 5 & 35.8 & 45.1 & $<0.05$ \\
All stations & 31.74 & 41.59 & $<0.05$ \\
\hline
\end{tabular}

maenas was compared by testing the average size of all crabs caught every second hour during the tidal cycle. These average sizes for the $6 \mathrm{~h}$ around high tide were compared with those for the $6 \mathrm{~h}$ around low tide, using Student's t-test for each of the 4 groups (Table 6). An example of how size of crabs varies with the tidal height is given in Fig. 3. There was a tendency for large green males to be caught around high tide in the 2 August samples, so that mean CW increased significantly at the time of high tide. This was not the case for green males in October. Furthermore, female crabs and non-green males caught throughout the year did not display this trend. The only exceptions were the green female crabs, of which significantly larger individuals were caught around high tide in October. The apparent correlation between size of females and time of high tide may be confounded by the fact that the high tides occurred at night when crabs were most active. The correlation between size and time of high tide in male crabs was based on data obtained in periods when high tides occurred in daylight hours.

\section{Does moult stage influence the free-running rhythms of adult male crabs?}

Differences in the ability of green and non-green male Carcinus maenas to express free-running rhythms in heart rate were detected. The results of periodogram analyses of the time series are shown in Table 7 . The data obtained indicate that green male $C$. maenas usually express a high degree of rhythmicity. None of the 8 green males examined were arrhythmic, 5 exhibited both circatidal and circadian rhythms, while 1 individual exhibited only circatidal heart rate rhythms. Two crabs displayed circadian rhythmicity in heart rate. Three of the 8 non-green male $C$. maenas did not display heart rate rhythms. Three others exhibited circatidal rhythms in heart rate while 4 crabs expressed circadian rhythms. Two of these latter crabs displayed both circatidal and circadian rhythmicity in heart rate. An example of a heart rate time series is given in Fig. 4, together with periodogram analysis of the rhythmicity.

Table 6. Carcinus maenas. Average carapace width (CW) of green and non-green male and female crabs collected at time of high or low tide over the summer and autumn collections. $p$ : significance level in a Student's $t$-test

\begin{tabular}{|c|c|c|c|c|c|c|c|c|c|c|c|}
\hline \multirow{2}{*}{$\begin{array}{l}\text { Sampling } \\
\text { date }\end{array}$} & \multicolumn{3}{|c|}{ Green male CW } & \multicolumn{3}{|c|}{ Non-green male CW } & \multicolumn{3}{|c|}{ Green female CW } & \multicolumn{2}{|c|}{ Non-green female CW } \\
\hline & High tide & Low tide & $\mathrm{p}$ & High tide & Low tide & $\mathrm{p}$ & High tide & Low tide & $\mathrm{p}$ & High tide Low tide & $\mathrm{p}$ \\
\hline 4 Aug 1992 & $45.1 \pm 8.7$ & $41.9 \pm 10.9$ & 0.04 & $52.1 \pm 9.9$ & $50.7 \pm 8.0$ & 0.50 & $37.1 \pm 6.1$ & $35.7 \pm 5.9$ & 0.42 & $44.2 \pm 6.2 \quad 40.6 \pm 6.6$ & 0.21 \\
\hline 18 Aug 1992 & $40.8 \pm 8.5$ & $38.0 \pm 8.4$ & 0.01 & $49.6 \pm 7.8$ & $52.5 \pm 5.5$ & 0.17 & $32.9 \pm 6.5$ & $32.7 \pm 6.2$ & 0.89 & $42.5 \pm 2.1 \quad 41.1 \pm 7.3$ & 0.80 \\
\hline 6 Oct 1992 & $36.3 \pm 8.5$ & $35.1 \pm 7.5$ & 0.33 & $46.8 \pm 8.9$ & $47.4 \pm 6.9$ & 0.84 & $33.8 \pm 5.5$ & $31.5 \pm 5.9$ & 0.02 & $36.6 \pm 5.9 \quad 36.6 \pm 4.7$ & 0.98 \\
\hline
\end{tabular}



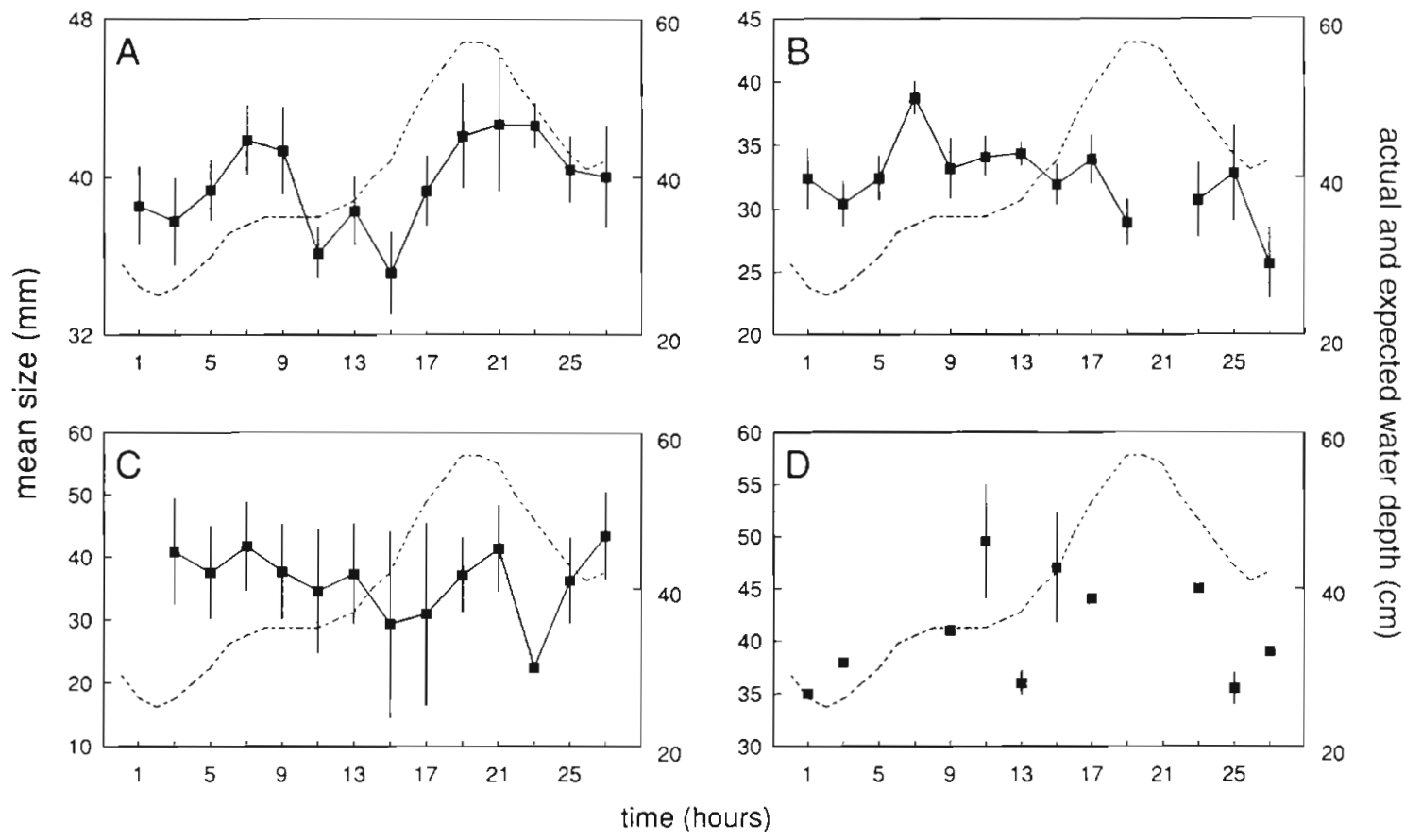

Fig. 3. Carcinus maenas. Variation in average carapace width of crabs collected every $2 \mathrm{~h}$. Subgroups of crabs were designated as (A) green males, (B) non-green males, (C) green females and (D) non-green females, with expected and recorded tidal changes. - average carapace width $\pm \mathrm{SEM}_{\mathrm{i}}----$ : actual tidal variation; shaded area: expected tidal changes

\section{DISCUSSION}

The times of sampling during the year were chosen randomly in relation to tidal and diel cycles. Ideally, seasonal comparisons should be made at the same stage in the lunar cycle (e.g. at new moon, or full moon; Atkinson \& Parsons 1973) or should be conducted with a sufficient number of sampling exercises in each season to randomise for tidal stage and diel phase (Hunter \& Naylor 1993). Furthermore, the use of a baited dropnet is clearly a biased method of estimating population dynamics, since it will select for the most actively foraging crabs. Crabs are variably attracted to bait depending on their moult stage, reproductive condition and nutritional state (Crothers 1968, Klein Breteler 1975). Despite these considerations, the results of the present study are useful because they permit identification of distinct morphological and physiological characteristics that were associated with different patterns of foraging behaviour in Carcinus maenas.

Seasonal variation in catch per dropnet was high in summer and autumn as expected from previous studies (Naylor 1962, Crothers 1968, Atkinson \& Parsons 1973, Rasmussen 1973, Hunter \& Naylor 1993). It was surprising, however, that the spring catch per dropnet was so low, in view of an average water temperature of $11.7^{\circ} \mathrm{C}$. Rasmussen (1973) reported spring migration from deep to shallow water when the water tempera- ture rose to 8 to $10^{\circ} \mathrm{C}$ in Isefjord, Denmark. Similarly, Atkinson \& Parsons (1973) found that activity of Carcinus maenas in the intertidal zone increases when water temperature rises above $8^{\circ} \mathrm{C}$. The low level of foraging activity in spring reported here could reflect the rapid rise in water temperature from 8 to $11.7^{\circ} \mathrm{C}$

Table 7. Carcinus maenas. Period (hours:minutes) of freerunning rhythms in heart rate of green and non-green adult male crabs detected by periodogram analysis. ID: individual;

CW: carapace width $(\mathrm{mm})$. nr: no rhythmicity detected

\begin{tabular}{|ccccc|}
\hline ID & CW & Colour & Circatidal & Circadian \\
\hline 1 & 50 & Green & $12: 20$ & $24: 20$ \\
2 & 53 & Green & $\mathrm{nr}$ & $24: 00$ \\
3 & 59 & Green & $12: 00$ & $24: 00$ \\
4 & 63 & Green & $\mathrm{nr}$ & $22: 40$ \\
5 & 50 & Green & $13: 00$ & $25: 00$ \\
6 & 50 & Green & $13: 00$ & $26: 00$ \\
7 & 50 & Green & $12: 00$ & $24: 00$ \\
8 & 53 & Green & $12: 40$ & $\mathrm{nr}$ \\
9 & 53 & Non-green & $12: 20$ & $\mathrm{nr}$ \\
10 & 52 & Non-green & $\mathrm{nr}$ & $\mathrm{nr}$ \\
11 & 49 & Non-green & $\mathrm{nr}$ & $24: 20$ \\
12 & 57 & Non-green & $\mathrm{nr}$ & $25: 20$ \\
13 & 58 & Non-green & $\mathrm{nr}$ & $\mathrm{nr}$ \\
14 & 52 & Non-green & $13: 00$ & $25: 20$ \\
15 & 63 & Non-green & $\mathrm{nr}$ & $\mathrm{nr}$ \\
16 & 56 & Non-green & $11: 40$ & $23: 40$ \\
& \multicolumn{5}{c}{} & \\
\hline
\end{tabular}


Fig. 4. Carcinus maenas. Free-running rhythms in heart rate of a green male crab (A) over $4 \mathrm{~d}$ and $(B)$ including the periodogram analyses. The part of the time series of heart rate starting from the arrow was used for periodogram analyses. : expected high tide $\rightarrow$ : expected nighttime from sunset to sunrise
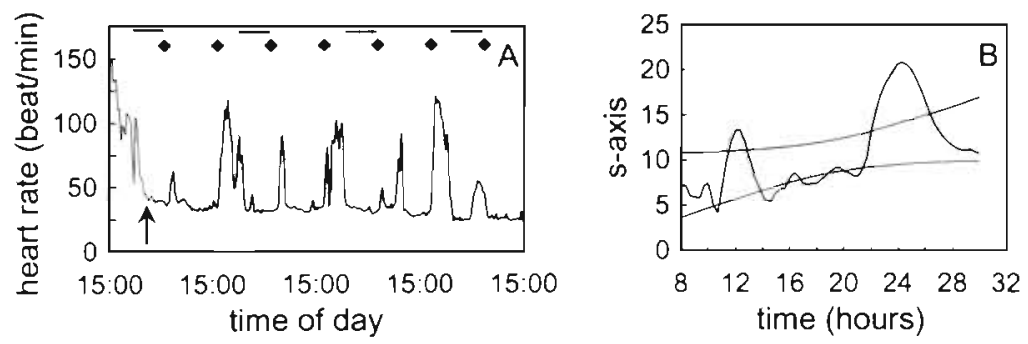

in the week immediately prior to the date of sampling (The Environmental Protection Department, Fyns Council, Denmark, pers. comm.). Thus, the crabs may not have had time to adapt their behaviour to the increase in water temperature. The low number of crabs caught per dropnet in winter is consistent with earlier reports of crabs being inactive at low temperatures and, as is evident in Table 3, they were collected only from the outer stations in deeper water.

The size distribution of colour forms of both male and female Carcinus maenas suggests that non-green forms are not apparent until crabs attain a CW of 30 to $35 \mathrm{~mm}$. Crabs are juvenile until then. Above $35 \mathrm{~mm}$ CW crabs become sexually mature and can delay the moult cycle by prolonging the intermoult stage $\left(\mathrm{C}_{4}\right)$. The minimum $\mathrm{CW}$ of an ovigerous female $C$. maenas has been reported to be about $34 \mathrm{~mm}$ (Berrill 1982, Reid et al. 1994).

The significantly higher catch of green male forms of Carcinus maenas may reflect the actual distribution of sex and colour in the environment, but bias due to the method of catching crabs cannot be ruled out since the part of the population that is actively foraging is likely to be caught more frequently. Interestingly, the literature indicates similar sex proportions in $C$. maenas populations when samples were obtained using crab pots located in the sublittoral zone (Rasmussen 1973, Hunter \& Naylor 1993)

The 3-way analysis of contingency for the August and October sampling exercises revealed that there were fewer non-green crabs in shallow water in early August and October. Lower numbers of females were present at the inner locations in late August whereas the number of females at Stn 0 was unexpectedly high in October. The dominance of non-green crabs in the subtidal zone reported by Warman et al. (1993) and Hunter \& Naylor (1993) was not apparent in the data presented here. The differences in expected and observed frequencies between single stations were not consistent among the inner and outer stations, from shallow to deeper water.

It is evident from the average catch of crabs in relation to tidal stage and diel phase that most crabs were caught at night. There was no clear tidal pattern in the frequency with which crabs were collected. Compar- isons of the size of the crabs, however, revealed that proportionally more adult crabs were collected around high tide times. Closer examination indicated that it was predominantly green adult males that were foraging actively and were caught in dropnets. Analysis of free-running rhythms in heart rate of green and nongreen adult male Carcinus maenas revealed a similar pattern; green males exhibited the most pronounced circatidal and circadian activity. The temperature and salinity at which experiments were conducted were chosen to be similar to those at the site of collection to avoid induction of rhythms by temperature changes (cooling; Naylor 1963) or by hypo-osmotic shock (Reid \& Naylor 1990).

The nocturnal nature of foraging activity of crabs may be an adaptation to minimise predation. Avian predation is an important factor in controlling the abundance of Carcinus maenas (Crothers 1968, Dare \& Edwards 1981, Dumas \& Witman 1993). This was evident in the fragments of crab carapace in gull Larus spp. excrement (author's pers. obs.) at the sampling stations used in this study. Gull feeding activity takes place in daylight when the birds can hunt by sight. Nocturnal foraging behaviour of $C$. maenas thus appears to be an adaptation to reduce such predation.

It is unclear why Carcinus maenas (particularly green males) in weakly tidal conditions express circatidal rhythmicity in foraging activity and circatidal rhythms in heart rate in constant conditions. There is, however, a small but consistent tidal change in the habitat where the population of C. maenas used in this study live, which was apparently sufficient to entrain circatidal rhythmicity. Hydrostatic pressure has been evaluated as a zeitgeber in the entrainment of circatidal rhythms of C. maenas, showing that 0.1 atm pressure change can induce such rhythmicity (Naylor \& Atkinson 1972). However, the data presented here suggest that a change of 0.01 to $0.03 \mathrm{~atm}$ is sufficient to entrain a rhythm (although other environmental factors may also influence entrainment). These findings are interesting to compare with studies on $C$. estuarii, which did not exhibit circatidal rhythmicity in locomotor behaviour (Naylor 1961, Warman et al. 1991). Apparently there is a behavioural difference between 
these 2 closely related species, even though they live in similar tidal conditions. The rhythmic behaviour of C. maenas requires further investigation, perhaps by following the behaviour of $C$. maenas along a tidal transect into non-tidal conditions to gain further insight into rhythm entraining factors.

Acknowledgements. We are grateful to the Family Eriksen for their hospitality at the field location. L. Aagaard, J. Aagaard, Dr P. Abelló, R. Andersen, P. Györkös and B. Styrishave volunteered long hours to help in the collection of field data. This work was funded by grants to M.H.D. from the Danish Natural Science Research Council and the Royal Society, UK.

\section{LITERATURE CITED}

Aagaard A, Andersen BB, Depledge MH (1991) Simultaneous monitoring of physiological and behavioural activity in marine organisms using non-invasive, computer-aided techniques. Mar Ecol Prog Ser 73:277-282

Aagaard A, Warman CG, Depledge $M H$, Naylor $E$ (in press) Dissociation of heart rate and locomotor activity during the expression of rhythmic behaviour in the shore crab Carcinus maenas. Mar Freshwat Behav Physiol

Atkinson RJA, Parsons AJ (1973) Seasonal patterns of migration and locomotor rhythmicity in populations of Carcinus. Neth J Sea Res 7:81-93

Berrill M (1982) The life cycle of the green crab Carcinus maenas at the northern end of its range. J Crust Biol 2(1):31-39

Crothers JH (1967) The biology of the shore crab Carcinus maenas (L.). 1. The background - anatomy, growth and life history. Fld Studies 2:407-434

Crothers JH (1968) The biology of the shore crab Carcinus maenas (L.) 2. The life of the adult crab. Fld Studies 2(5):579-614

Dare PJ, Edwards DB (1981) Underwater television observations on the intertidal movements of shore crabs, Carcinus maenas, across a mudflat. J mar biol Ass UK 61:107-116

Depledge MH, Andersen BB (1990) A computer-aided physiological monitoring system for continuous, long-term recording of cardiac activity in selected invertebrates. Comp Biochem Physiol 96A:473-477

Dumas JV, Witman JD (1993) Predation by herring gulls (Larus argentatus Coues) on two rocky intertidal crab species [Carcinus maenas (L.) \& Cancer irroratus Say]. $\mathrm{J}$ exp mar biol Ecol 169:89-101

This article was submitted to the editor
Hunter E, Naylor E (1993) Intertidal migration by the shore crab Carcinus maenas. Mar Ecol Prog Ser 101:131-138

Kaiser MJ, Hughes RN, Reid DG (1990) Chelal morphometry, prey-size selection and aggressive competition in green and red forms of Carcinus maenas (L.). J exp mar Biol Ecol 140: $121-134$

Klein Breteler WCM (1975) Food consumption, growth and energy metabolism of juvenile shore crabs, Carcinus maenas. Neth J Sea Res 3-4:255-272

McGaw IJ, Kaiser MJ, Naylor E, Hughes RN (1992) Intraspecific morphological variation related to the moult-cycle in colour forms of the shore crab Carcinus maenas. J Zool, Lond 228:351-359

McGaw IJ, Naylor E (1992) Distribution and rhythmic locomotor patterns of estuarine and open-shore populations of Carcinus maenas. J mar biol Ass UK 72.599-609

Naylor E (1958) Tidal and diurnal rhythms of locomotory activity in Carcinus maenas (L.). J exp Biol 35:602-610

Naylor E (1961) Spontaneous locomotor rhythms in Mediterranean Carcinus. Pubbl Staz Zool Napoli 32:58-63

Naylor E (1962) Seasonal changes in a population of Carcinus maenas (L.) in the littoral zone. J Anim Ecol 31:601-609

Naylor E (1963) Temperature relationships of the locomotor rhythm of Carcinus. J exp Biol 40:669-679

Naylor E, Atkinson RJA (1972) Pressure and the rhythmic behaviour of inshore marine animals. Symp Soc exp Biol 26:395-415

Rasmussen E (1973) Systematics and ecology of the Isefjord marine fauna (Denmark). Ophelia p 211-221

Reid DG, Abelló P, Warman CG, Naylor E (1994) Size-related mating success in the shore crab Carcinus maenas (Crustacea: Brachyura). J Zool, Lond 232:397-407

Reid DG, Naylor E (1990) Entrainment of bimodal circatidal rhythms in the shore crab Carcinus maenas. J Biol Rhythms 5(4):333-347

Reid DG, Warman CG, Naylor E (1993) Ontogenetic changes in zeitgeber action in the tidally rhythmic behaviour of the shore crab Carcinus maenas. Proc 27th Eur Mar Biol Symp, Dublin, p 129-133

Warman CG, Abelló P, Naylor E (1991) Behavioural responses of Carcinus mediterraneus Czerniavsky, 1884 to changes in salinity. Scientia mar 53:637-643

Warman CG, Reid DG, Naylor E (1993) Variation in the tidal migratory behaviour and rhythmic light-responsiveness in the shore crab, Carcinus maenas. J mar biol Ass UK 73 : $355-364$

Williams JA, Naylor E (1978) A procedure for the assessment of significance of rhythmicity in time-series data. J Chronobiol 5:435-444

Manuscript first received: October 31, 1994

Revised version accepted: March 7, 1995 